\title{
Spermatogenic Efficacy of Pausinystalia yohimbe (K. Schum.) Pierre ex Beille Roots in Male Rats
}

\author{
Adekunle O. Ojatula* \\ Phytomedicine Research Centre, Botany Unit, Department of Biological Sciences, Faculty of Science, Ondo State University of Science and \\ Technology, Okitipupa, Nigeria
}

Received: 06/05/2020 Accepted: 03/06/2020_ Published: 20/06/2020

\begin{abstract}
Background: The roots of Pausinystalia yohimbe have been traditionally acclaimed as aphrodisiac. In the present study, methanol extract of the root was evaluated for its effect on sexual orientation behaviour and spermatogenesis in albino Wistar rats.

Methods: Forty five (45) male albino rats were randomly divided into five groups of nine rats each. Rats in group I (control) were administered $1 \mathrm{~mL} / \mathrm{kg}$ body weight distilled water (vehicle), group II received $5 \mathrm{mg} / \mathrm{kg}$ body weight sildenafil citrate (Viagra), while those in groups III, IV, and V were given 25,50 , and $100 \mathrm{mg} / \mathrm{kg}$ body weight, respectively, of methanol extract of Pausinystalia yohimbe root in the same volume. Female albino rats were made receptive by hormonal treatment. Sexual orientation behaviour parameters were monitored on days 1,7 and 14 by pairing with receptive females. A change in sexual orientation behaviuor was assessed by orientation towards female, towards environment and towards self, while spermatogenic activity was evaluated on day 14 .

Results: Administration of the extract had pronounced effect on sexual orientation behaviour of male towards the female rats on days 7 and 14. Males treated with the extract displayed more frequent and vigorous anogenital sniffing and mounting as compared to untreated animals. Libido was also at increase in extract treated male rats. The extract had stimulated the spermatogenetic activity and accessory reproductive organs performance in albino rats. The increased spermatogenesis in extract treated groups was confirmed by change in histoarchitecture as evidenced by increase in number of spermatogenic elements and parameters.

Conclusion: $P$. yohimbe exhibited remarkable increase in sexual orientation, libido and spermatogenic activity which are some of the indices that determine the ability of a male to produce viable spermatozoa. These findings support the folk use of this plant as an aphrodisiac.
\end{abstract}

Keywords: Aphrodisiac, Herbal drugs, Pausinystalia yohimbe, Sexual orientation, Spermatogenesis

\section{Introduction}

Sexual relationships are among the most important social and biological relationships in human life; and sexual health is an important component of an individual's quality of life and well-being. In human society, one of the main aims of marriage is procreation (reproduction) to ensure the continuity of an individual's lineage and, more importantly, for sexual fulfillment of both partners. For life to continue, an organism must reproduce itself before it dies (1). In Homo sapiens, reproduction is initiated by the mating of a male with a female in sexual intercourse which facilitates the coming together of sperm and egg for the purpose of fertilization (2). For there to be a normal sexual intercourse and sexual fulfillment in males, the male sexual organs (the copulatory organ, that is, the penis) and factors relating to erection must function normally. The recurrent or repeated inability of the male to perform a satisfactory sexual function or any disorder that interferes with the full sexual response cycle is a major problem facing the reproductive process, and it varies markedly in degree (3).

Perpetuation of one's race is the dogma of all living organisms. All living organisms strive to achieve this through the process of reproduction, which is the vital process that enables a species to represent itself in the following generation in the form of its offspring. Different contraceptive methods are in practice for family planning (i.e., for population control). At the same time, there are couples who

Corresponding author: Adekunle O. Ojatula, Phytomedicine Research Centre, Botany Unit, Department of Biological Sciences, Faculty of Science, Ondo State University of Science and Technology, Okitipupa, Nigeria. E-mail: kunletula@yahoo,com. are facing the problems of infertility. Infertility is the diminished ability or the inability to conceive and have offspring. Statistics reveal that more than 2 million married couples are now experiencing problems with infertility. Approximately 6 million women between the ages of 16 and 45 have infertility issues and about $30 \%$ of cases are found in the man alone (4). But infertility is not always a women's problem. Infertilities are due to the women (female factors) or man (male factors) or caused by a mixture of male and female factors or by unknown factors (5).

There are different types of assisted reproductive technologies that are used to treat infertility. These treatments are highly effective when it comes to increasing the chances of conception, but are very expensive and are often associated with a number of physical and emotional side effects (6). About $30 \%-50 \%$ of problems in infertile couples are due to male infertility (5). Present day's people are turning to herbal remedies to improve this infertility problem as they are easily approachable to common man; and researches are carried out to find out the plant products that can be used to treat this kind of infertility problems. Several plant extracts have long been used to treat problems with fertility. In fact, evidence of the use of herbal extracts for male and female fertility dates all the way back to 200 A.D (4).

Infertility has been a recurring problem among male and female individuals. Today, orthodox medicine has almost exceeded its limits in resolving problem of infertility. This is why the use of phytomedicine is becoming a main stay in the treatment of infertility. It has been reported that alternative medicines have proven efficacious in the treatment of human infertility (4). A multi-faceted therapeutic approach to improving male infertility involves identifying harmful 
environmental and occupational risk factors, while correcting underlying nutritional imbalances to encourage optimal sperm production and function. A number of nutritional therapies have been shown to improve sperm counts and motility, including camitine and zinc. Numerous antioxidants have also proven beneficial in treating male infertility such as vitamins $\mathrm{C}$ and E (7). Specific botanical medicines have been documented in several studies as having a positive effect on sperm parameters. Chen et al. (8) found extracts of Panax notoginseng capable of significantly enhancing in vitro sperm motility.

Hitherto, sexuality is a complex, multi-dimensional phenomenon that incorporates biological, psychological, interpersonal and behavioural dimensions. Sexual behaviour in male rats consists of three distinct phases, viz., mount, intromission and ejaculation. Male sexual performance is a phenomenon associated with male sexual response cycle components; and a normal male sexual response cycle is functionally divided into five interrelated events, viz., libido, erection, ejaculation, orgasm, and detumescence (1). These must occur in a defined timely sequential steps for a normal sexual function. Any hinderance in the effective performance/completion of the sexual response cycle or the disruption of its ordered sequence leads to male sexual dysfunction (9).

Androgens play a crucial role in the development of secondary male sexual organs such as the epididymis, vas deferens, seminal vesicle, prostrate, and penis. Furthermore, androgens are needed for puberty, male fertility, and male sexual function (10). Testosterone is the principal androgen secreted by the testes, and stimulated by luteinizing hormone (LH). One of the principal effects of testosterone within the testes is the stimulation of spermatogenesis in seminiferous tubules. The effect of testosterone on libido may require conversion of testosterone to estradiol in the hypothalamus. The mechanisms whereby testosterone affects muscle, bone, and the erythron do not appear to require prior molecular conversion (11), and androgens are known to influence nitric oxide (NO) production in the brain as well in the periphery (12). Plant-derived chemicals that have sex-enhancing and spermatogenic potentials in animals, man inclusive, have received a great attention and have become known worldwide as alternative therapy in enhancing fertility both in male and female factors. These include saponins from Fadogia agrestic, Terminalia catappa, Tribulus terestris and Bulbine natalensis (13). These drugs were discovered following some ethnomedicinal information on medicinal plants. Among the plants, Pausinystalia yohimbe root has been reported to be used for enhancing male sexual functions and fertility in Southwestern, Nigeria.

Pausinystalia yohimbe (K. Schum.) Pierre ex Beille belongs to the family Rubiaceae. It is an evergreen species growing in West and Central Africa in lowland forests. The tree grows about $30 \mathrm{~m}$ tall, with a straight boles/trunk that is rarely larger than $50-60 \mathrm{~cm}$ in diameter. The bark is grey to reddish-brown, with longitudinal fissures, easy to peel and bitter-tasting. The inner bark is pinkish and fibrous. The sapwood is yellowish and the heartwood is ochre-yellow; the wood is fine-grained and relatively dense and moderately hard. The leaves grow in groups of three, with short (about 2 $\mathrm{cm}$ ) petioles. The blades are oval-shaped, $11-47 \mathrm{~cm}$ long and 5-17 cm wide. It exhibits tap root system, and the root can be erect, bend, folded and branching. The fruit (Jan. to March) is spindle-shaped, measuring up to $2 \mathrm{~cm}$ long with narrowly elongated winged seeds. Its geographical spread is from south-western Nigeria to Gabon and Zaire. Yorubas call it 'Idagbon', Ibos call it 'Likiba' while Hausas call it 'Burantashi' (14). The extract of the root of Pausinystalia yohimbe (K. Schum) Pierre ex Beille is one of such sex tonics that is largely used by the people as an aphrodisiac with the ability to increase sexual and fertility potency, and virility.

To the best of my knowledge, this is the first time in literature, reporting the spermatogenic effect of Pausinystalia yohimbe root; as compared to the frequently used plant material of Pausinystalia yohimbe, the stem-bark, in the open literature. The plant's root is reported in the folk medicine of the indigenous people of Ilaje area of Ondo State, Nigeria to be more efficacious and potent in enhancing reproductive activity in male than the stem-bark (15). I showed in a research study that methanol extract of $P$. yohimbe root increases sexual behaviour and mating performance in male rats (16). Therefore, it is my interest to process this plant's root for systemic study on its stimulatory effect with a view to explain the effect of the extract on spermatogenesis and sexual behaviour in male rats.

\section{Materials and Methods \\ 2.1 Animal stock}

The protocol for experimentation was approved on 12th January, 2017 by the Ethical Committee (Ref. no: UNIBEN/NOEC/PBB_LSC/365/5) on Experimental Animal Use and Care of the Faculty of Life Sciences, University of Benin, Benin City, Nigeria. Sexually matured, healthy, albino rats of Wistar strain (Rattus norvegicus), weighing about 230$300 \mathrm{~g}$ (male), and 150-180 g (female) were obtained from the animal holding unit of the Department of Pharmacology and Toxicology, University of Benin, and were used for the experiments. The animals were allowed to undergo acclimatization period of seven (7) days and were housed in a ventilated wooden cage. They were kept at room temperature $28-30^{\circ} \mathrm{C}$ under natural light and dark cycle with free access to pelleted feed and tap water. Good hygiene was maintained by constant cleaning and removal of faeces from the cage on daily basis.

\subsection{Plant material}

Fresh roots of Pausinystalia yohimbe were obtained from Ugowan Village, near the boundary of Okomu National Park, Udo, Edo State, Nigeria during April to May 2015. The plant sample was identified and confirmed at the Herbarium of the Department of Plant Biology and Biotechnology of the University of Benin, Benin City, Edo State, Nigeria with the voucher number UPBHx1066.

\subsection{Preparation of plant material}

The fresh roots of Pausinystalia yohimbe collected were thoroughly washed and air dried inside the laboratory until constant weight was obtained. They were pulverized using an electric blender (RN4S, Mayer, China) and sieved to obtain the powdered form. One thousand two hundred grams $(1,200$ g) of the powdered form was extracted in 99\% absolute methanol using Soxhlet apparatus. The extraction was carried out in cycles at a temperature of $50^{\circ} \mathrm{C}$, and each cycle lasted for 48 hours. Extract was evaporated to near dryness and as well, concentrated on a water bath under reduced pressure and low temperature. The slurry from methanol extract was later weighed and reconstituted in distilled water to give the required doses used in the study. 


\subsection{Drugs, assay kits and other reagents}

Estradiol benzoate and progesterone were purchased from Sigma-Aldrich from China and USA. Sildenafil citrate (Viagra) was obtained from a community pharmacy outlet in Okitipupa, Ondo State. The testosterone assay kit was procured from Monobind Inc., USA while every other chemicals used were of analytical grade.

\subsection{Preparation of test samples}

Methanol extract was prepared in Tween $80(1 \%)$, suspended in $1 \mathrm{~mL} / \mathrm{kg}$ distilled water and sildenafil citrate $(0.05 \%)$ was also suspended in $1 \mathrm{~mL} / \mathrm{kg}$ distilled water and administered orally using intragastric catheter.

\subsection{Treatment}

A total of 45 male rats, 3 months old (weighing $230-$ $300 \mathrm{~g}$ ) were selected for study. They were randomly divided into five groups of nine rats each, and ear tags and colour codes were given to identify each animal. Group I animals served as the negative control and received only vehicle i.e., 1 $\mathrm{mL} / \mathrm{kg}$ distilled water. Animals in Group II received dose of sildenafil citrate (Viagra) $5 \mathrm{mg} / \mathrm{kg}$ orally daily for 14 days and served as positive control for sexual orientation behaviour studies. Groups III, IV and V were administered with methanol extract of Pausinystalia yohimbe root on a daily dosage of 25,50 and $100 \mathrm{mg} / \mathrm{kg}$ body weight respectively for 14 days.

Two days (48 hours) prior to the commencement of the experiment, female rats 2.5 months old (weighing $150-180$ g) were selected and each of them was administered with estradiol benzoate $(10 \mu \mathrm{g} / \mathrm{kg})$. Four (4) hours prior to the exposure to males, each female rat was also given subcutaneous injection of progesterone $(0.5 \mathrm{mg} / \mathrm{kg})$ to ensure that the female rats were in oestrous, this being the time when they were most receptive to fertilization (1). Half hour after the dose administration on day 1 (after a single dose), day 7 (after seven doses, once daily) and day 14 (after fourteen doses, once daily), male rats from each of the group were individually placed in separate cages and were monitored on experimental periods of days 1,7 and 14 for sexual orientation behaviour activity.

\subsection{Determination of sexual orientation behaviour activity}

The test was carried out by the method of Islam et al. (17), modified by Sharma et al. (18). Healthy and sexually experienced male wistar rats $(230-300 \mathrm{~g})$ that were showing brisk sexual activity were selected for the study. They were divided into five groups of nine rats each, and kept single in separate cages during the experiment. Groups I, represented the negative control, which received $1 \mathrm{~mL} / \mathrm{kg}$ of distilled water orally. Group II served as positive control (standard drug group) and given suspension of Sildenafil citrate (Viagra) orally at the dose of $5 \mathrm{mg} / \mathrm{kg}$, one hour to the commencement of the experiment.

Groups III, IV and V represented the test groups and received suspension of the methanol extract of $P$. yohimbe root orally at the doses of $25 \mathrm{mg} / \mathrm{kg}, 50 \mathrm{mg} / \mathrm{kg}$, and $100 \mathrm{mg} / \mathrm{kg}$ respectively, daily for 14 days at 18:00 hour i.e., 6:00 am. The receptivity of the female rats was confirmed before the test by exposing them to male rats, other than the negative control, test groups and standard drug group of rats. The most receptive females were selected for the study. The experiment was conducted at 20:00 hour i.e., 8:00 pm in the laboratory under light of dim intensity. The receptive female rats were introduced into the cages of the rats with 1 female to 1 male ratio. The orientation activity was carried out on day 1, 7 and 14 of experiment and was analyzed in three segments with little modification (17). Orientation behaviour of male rats was determined using the following methods of scoring as described by Zade et al. (19). Orientation towards female - (1 for every sniffing, and 2 for every licking). Orientation towards self - ( 1 for every non-genital grooming, and 2 for every genital grooming). Orientation towards environment ( 1 for every exploration, 2 for every raring and 3 for every climbing). Furthermore, the observation for mating behaviour was immediately commenced and continued for one hour observatory period. The test was terminated if the male failed to evince sexual interest. If the female did not show receptivity she was replaced by another artificially warmed female. The occurrence of events and phases of mating were recorded on audio video-cassette (Sony Handycam, China) as soon as they appeared. Their disappearance was also recorded. Later, the frequencies and sexual behaviour phases were determined from cassette transcriptions for test of libido.

\subsection{Test for libido}

The methanol extract of $P$. yohimbe root at 50 and 100 $\mathrm{mg} / \mathrm{kg}$ were found to be active amongst the three treatments in sexual orientation behaviour. Hence it was subjected to a detailed investigation for the study of test for libido. The level of sexual desire of the male rats was determined by the method described in Zade and Dabhadkar (20). Sexually experienced male albino rats were divided into five groups of three (3) rats each; Groups I, represented the negative control, which received $1 \mathrm{~mL} / \mathrm{kg}$ of distilled water orally. Group II served as positive control (standard drug group) and given suspension of Sildenafil citrate (Viagra) orally at the dose of 5 $\mathrm{mg} / \mathrm{kg}$, one hour to the commencement of the experiment. Groups III, IV and V represented the test groups and received suspension of the methanol extract of $P$. yohimbe root orally at the doses of $25 \mathrm{mg} / \mathrm{kg}, 50 \mathrm{mg} / \mathrm{kg}$, and $100 \mathrm{mg} / \mathrm{kg}$ respectively, daily for 14 days at 18:00 hour $(6: 00 \mathrm{am})$. The female rats were made receptive by hormonal treatment and all the rats were accustomed to the testing condition as described in mating behaviour test. The libido test was carried out using the mounting frequency (MF) on the evening of day 14 at 20:00 hour (8:00 pm). Each rat was placed individually in a cage and the receptive female rat was placed in same cage. At the point of starting observations, there was exhibition of actively pronounced sexual behaviour, which invariably, led to mating performance by the treatment groups. And the numbers of mountings were noted. The rats were also observed for intromission, and ejaculation - usually characterized by longer, deeper pelvic thrusting and slow dismount followed by a period of reduced activity.

\subsection{Effect on spermatogenesis}

The method reported by Saksena and Dixit (21) as modified by Tharkur and Dixit (22) was used. In brief, after 14 days of treatment the body weights of animals were taken after which the animals of controls as well as treated groups of rats were sacrificed by rapid decapitation. Testes were removed and cut into small pieces, fixed in Bovine's fixative, dehydrated with varying percentage of ethanol for histological examinations/studies. Sections were cut $(6 \mu)$, stained with eosin and analyzed microscopically. Histometric 
measurements such as diameter of testes, seminiferous tubules and Leydigs cell nucleus were made by random selection of 30 circulars sections by using ocular and stage micrometers. The numbers of different spermatogenic elements were also determined.

Furthermore, the motility of the spermatozoa was evaluated with regards to two variables: Progressive motility (PM), and non-progressive motility (NPM), using the method described, and modified by Dostal et al. (23), a drop of sperm cell from the petri dish was taken with a micro Pasteur pipette, and dispensed on a grease free clean slide covered with a transparent cover slip, and viewed under the microscope (x 10 and $\mathrm{x}$ 40) objective lens. The motility was scored in percentage according to their motile nature as progressively motile, and non-progressively motile $(24,25)$. The counting of sperm cells was done by making a solution of 1:20 dilution ratio of the spermatozoa with $10 \%$ formal saline in a test tube. The sperm cell counting chamber was charged, and a drop of the dilution was added into the counting chamber, and viewed under the microscope with the (x10) objective lens. Finally, sperm cells were counted and scored in $\times 10^{6} / \mathrm{mm}^{3}(26)$.

\subsection{Statistical analysis}

The results were expressed as mean \pm standard error of mean of nine replicates. All the mean values were statistically analysed by using one way analysis of variance (ANOVA) followed by Duncan's multiple range test. The values were judged significant if $p<0.05$. The statistical package for social sciences (SPSS) computer software (version 20) and Microsoft Excel (2013) software were used for data analysis.

\section{Results}

3.1 Effect of the methanol extract of Pausinystalia yohimbe root on sexual orientation behaviour

In this study, the methanol extract of Pausinystalia yohimbe root at the doses of 25,50 and $100 \mathrm{mg} / \mathrm{kg}$ body weight did not influence the orientation behaviour of the extract treated rats on day 1 , except the exploration (activity towards environment) which was non-significantly $(p>0.05)$ decreased compared to negative control rats (Table 1). In contrast, the standard drug (Sildenafil citrate) influenced the orientation behaviour of male rats on day 1 with nonsignificant $(p>0.05)$ increase in licking, anogenital smelling, exploration, raring, genital and non-genital grooming when compared to negative control rats. However, on day 7 and day 14 , the plant extract at the dose levels investigated markedly influenced the sexual orientation behaviour of the extract treated rats, which showed more attraction towards female rats. The studies, on day 7 , revealed increase in number of licking, and significant increase in the anogenital smelling ( $p$ $<0.05$ ) of extract treated male rats towards receptive females, comparable to the standard drug treated group of rats and the negative control. The behavioural assessment of rats towards environment (exploration and raring) was non-significantly decreased in extract treated and standard drug groups.

Table 1: Effect of Pausinystalia yohimbe methanol root extract on sexual orientation activity in male rats monitored on day 1

\begin{tabular}{|c|c|c|c|c|c|c|c|c|}
\hline \multirow{2}{*}{\multicolumn{2}{|c|}{ Groups }} & \multicolumn{2}{|c|}{ Activity score towards female } & \multicolumn{3}{|c|}{ Activity score towards environment } & \multicolumn{2}{|c|}{ Activity score towards self } \\
\hline & & Licking & $\begin{array}{l}\text { Anogenital } \\
\text { smelling } \\
\text { (sniffing) } \\
\end{array}$ & Exploration & Raring & Climbing & $\begin{array}{l}\text { Non-genital } \\
\text { grooming }\end{array}$ & $\begin{array}{l}\text { Genital } \\
\text { grooming }\end{array}$ \\
\hline Negative control & & $0.67 \pm 0.76$ & $1.00 \pm 0.00$ & $3.00 \pm 0.58$ & $2.67 \pm 1.76$ & $0.00 \pm 0.00$ & $0.67 \pm 0.33$ & $0.67 \pm 0.57$ \\
\hline Sildenafil citrate & $(5 \mathrm{mg} / \mathrm{kg})$ & $1.33 \pm 0.67$ & $1.33 \pm 0.31$ & $2.33 \pm 0.88$ & $2.00 \pm 1.15$ & $0.00 \pm 0.00$ & $1.33 \pm 0.31$ & $2.67 \pm 0.67$ \\
\hline $25 \mathrm{mg} / \mathrm{kg}$ & & & $0.00 \pm 0.00$ & $1.67 \pm 0.33$ & $0.00 \pm 0.00$ & $0.00 \pm 0.00$ & $0.00 \pm 0.00$ & $0.00 \pm 0.00$ \\
\hline $50 \mathrm{mg} / \mathrm{kg}$ & & $0.00 \pm 0.00$ & $0.00 \pm 0.00$ & $1.33 \pm 0.31$ & $0.00 \pm 0.00$ & $0.00 \pm 0.00$ & $0.00 \pm 0.00$ & $0.00 \pm 0.00$ \\
\hline $100 \mathrm{mg} / \mathrm{kg}$ & & $0.00 \pm 0.00$ & $0.00 \pm 0.00$ & $1.00 \pm 0.00$ & $0.00 \pm 0.00$ & $0.00 \pm 0.00$ & $0.00 \pm 0.00$ & $0.00 \pm 0.00$ \\
\hline
\end{tabular}

Table 2: Effect of Pausinystalia yohimbe methanol root extract on orientation activity in male rats monitored on day 7

\begin{tabular}{|c|c|c|c|c|c|c|c|}
\hline \multirow[b]{2}{*}{ Groups } & \multicolumn{2}{|c|}{$\begin{array}{l}\text { Activity score towards } \\
\text { female }\end{array}$} & \multicolumn{3}{|c|}{ Activity score towards environment } & \multicolumn{2}{|c|}{ Activity score towards self } \\
\hline & Licking & $\begin{array}{l}\text { Anogenital } \\
\text { smelling } \\
\text { (sniffing) }\end{array}$ & Exploration & Raring & Climbing & $\begin{array}{l}\text { Non-genital } \\
\text { grooming }\end{array}$ & $\begin{array}{l}\text { Genital } \\
\text { grooming }\end{array}$ \\
\hline Negative control & $0.67 \pm 0.76$ & $0.67^{\mathrm{b}} \pm 0.57$ & $4.00 \pm 1.53$ & $3.33 \pm 2.40$ & $0.00 \pm 0.00$ & $1.00 \pm 0.00$ & $0.67 \pm 0.57$ \\
\hline Sildenafil citrate $(5 \mathrm{mg} / \mathrm{kg})$ & $2.00 \pm 1.15$ & $1.67^{\mathrm{b}} \pm 0.88$ & $2.67 \pm 1.20$ & $2.00 \pm 1.15$ & $0.00 \pm 0.00$ & $1.33 \pm 0.33$ & $2.00 \pm 1.15$ \\
\hline $25 \mathrm{mg} / \mathrm{kg}$ & $2.67 \pm 0.67$ & $2.67^{\mathrm{a}} \pm 1.20$ & $2.33 \pm 0.88$ & $1.33 \pm 0.66$ & $0.00 \pm 0.00$ & $2.00 \pm 0.58$ & $2.67 \pm 1.76$ \\
\hline $50 \mathrm{mg} / \mathrm{kg}$ & $4.00 \pm 1.15$ & $4.33^{\mathrm{a}} \pm 1.86$ & $1.67 \pm 0.57$ & $1.33 \pm 0.67$ & $0.00 \pm 0.00$ & $2.33 \pm 0.88$ & $4.00 \pm 2.00$ \\
\hline $100 \mathrm{mg} / \mathrm{kg}$ & $3.33 \pm 1.33$ & $3.00^{\mathrm{a}} \pm 0.58$ & $2.00 \pm 1.00$ & $1.33 \pm 1.31$ & $0.00 \pm 0.00$ & $2.00 \pm 0.58$ & $3.33 \pm 0.67$ \\
\hline
\end{tabular}

$(n=5), p<0.05-$ Significant, $p>0.05-$ Not Significant

Different letters in superscript across the columns are significant from others

Table 3: Effect of Pausinystalia yohimbe methanol root extract on orientation activity in male rats monitored on day 14

\begin{tabular}{|c|c|c|c|c|c|c|c|}
\hline \multirow[b]{2}{*}{ Groups } & \multicolumn{3}{|c|}{ Activity score towards environment } & \multicolumn{4}{|c|}{ Activity score towards self } \\
\hline & Licking & $\begin{array}{l}\text { Anogenital smelling } \\
\text { (sniffing) }\end{array}$ & Exploration & Raring & Climbing & $\begin{array}{l}\text { Non-genital } \\
\text { grooming }\end{array}$ & $\begin{array}{l}\text { Genital } \\
\text { grooming }\end{array}$ \\
\hline Negative control & $0.67^{\mathrm{b}} \pm 0.76$ & $0.67^{\mathrm{b}} \pm 0.33$ & $4.33 \pm 1.86$ & $4.00 \pm 2.00$ & $0.00 \pm 0.00$ & $1.00 \pm 0.58$ & $0.67 \pm 0.67$ \\
\hline Sildenafil citrate & $1.33^{\mathrm{b}} \pm 0.67$ & $0.67^{b} \pm 0.33$ & $3.00 \pm 0.58$ & $2.67 \pm 1.76$ & $0.00 \pm 0.00$ & $1.33 \pm 0.88$ & $2.00 \pm 1.15$ \\
\hline $25 \mathrm{mg} / \mathrm{kg}$ & $3.33^{\mathrm{a}} \pm 0.67$ & $2.67^{\mathrm{a}} \pm 0.67$ & $2.33 \pm 0.33$ & $1.33 \pm 0.67$ & $0.00 \pm 0.00$ & $2.33 \pm 0.33$ & $3.33 \pm 0.67$ \\
\hline $50 \mathrm{mg} / \mathrm{kg}$ & $5.33^{\mathrm{a}} \pm 0.67$ & $3.33^{\mathrm{a}} \pm 0.88$ & $1.33 \pm 0.33$ & $0.67 \pm 0.57$ & $0.00 \pm 0.00$ & $1.67 \pm 0.67$ & $4.00 \pm 2.00$ \\
\hline $100 \mathrm{mg} / \mathrm{kg}$ & $4.00^{\mathrm{a}} \pm 1.15$ & $3.00^{\mathrm{a}} \pm 0.577$ & $1.67 \pm 0.33$ & $2.00 \pm 0.00$ & $0.00 \pm 0.00$ & $0.67 \pm 0.57$ & $2.67 \pm 0.67$ \\
\hline
\end{tabular}

$(n=5), p<0.05-$ Significant, $p>0.05-$ Not Significant

Different letters in superscript across the columns are significant from others 
The studies on the genital and non-genital grooming of male rats revealed that there was non-significant increase in genital and non-genital grooming $(p>0.05)$ in all extract treated groups compare with the negative control group. The standard drug group of rats also showed non-significant increase in genital and non-genital grooming of male rats as compared to negative control group (Table 2). Furthermore, on day 14 , the studies revealed significant increase in number of licking $(p<0.05)$ and in the anogenital smelling $(p<0.05)$ of extract treated male rats towards receptive females, comparable to the controls. The behavioural assessment of rats towards environment (exploration and raring) was nonsignificantly decreased in extract treated and standard drug groups. The studies revealed increase $(p>0.05)$ in genital and non-genital grooming in all extract treated groups as compared with the negative control group. The standard drug also shows non-significant increase in genital and non-genital grooming of male rats as compared to negative control group (Table 3).

\subsection{Effect of Pausinystalia yohimbe methanol root extract on libido}

The results obtained in the test for libido showed that the root extract of $P$. yohimbe at the doses of 25, 50 and 100 $\mathrm{mg} / \mathrm{kg}$, increased the Mounting Frequency (MF) $(p>0.05)$ as compared to negative control group. The standard drug also increased the MF $(p>0.05)$ as compared to negative control rats. Intromission was observed in experimental treated groups of rats, and standard drug group, while it was absent in negative control, however, ejaculation was noted only at the doses of 50 and $100 \mathrm{mg} / \mathrm{kg}$ body weight (Table 4 ).

\subsection{Effects of Pausinystalia yohimbe root on spermatogenic elements, and parameters}

The extract manifested increased spermatogenesis as evident by high number of spermatozoa in seminiferous tubules, and which is evident by increase in spermatogenic elements of the extract treated groups of rats as compared to control and standard drug groups (Table 5 and Plates 3-5).

The influence of $25 \mathrm{mg} / \mathrm{kg}, 50 \mathrm{mg} / \mathrm{kg}$ and $100 \mathrm{mg} / \mathrm{kg}$ body weight of $P$. yohimbe methanol root extract on sperm count and motility is illustrated in Table 6 . The plant extract, nonsignificantly $(p>0.05)$ decreased the sperm's progressive motility at the dose of $25 \mathrm{mg} / \mathrm{kg}$. However, progressive motility noticeably increased at $50 \mathrm{mg} / \mathrm{kg}$ and $100 \mathrm{mg} / \mathrm{kg}$ respectively. Sperm was immotile (non-progressive) and/or moving in random directions. Non-progressive motility increased $(p>0.05)$ at the dose of $25 \mathrm{mg} / \mathrm{kg}$, but decreases at the doses of $50 \mathrm{mg} / \mathrm{kg}$ and $100 \mathrm{mg} / \mathrm{kg}$. Meaning, progressive motility of spermatozoa increases, while non-progressive motility decreases in a dose dependent manner. The extract increased sperm count of experimental rats at all dose levels when compared with the control. The standard drug (Sildenafil citrate) also increased the sperm count but decreased sperm's progressive motility, while non-progressive motility was increased. Succinctly, sperm count of extract treated groups of rats were increasing in a dose dependent manner.

Table 4: Effect of Pausinystalia yohimbe methanol root extract on mounting frequency (test for libido) in male rats

\begin{tabular}{llll}
\hline Groups & Mounting Frequency $(\mathrm{MF})$ & Intromission Frequency (IF) & Ejaculation (EJ) \\
\hline Negative control & $0.43 \pm 0.31$ & $0.00 \pm 0.00$ & Absent \\
Sildenafil citrate $(5 \mathrm{mg} / \mathrm{kg})$ & $0.67 \pm 0.33$ & $0.33 \pm 0.13$ & Absent \\
$25 \mathrm{mg} / \mathrm{kg}$ & $1.33 \pm 0.13$ & $0.67 \pm 0.33$ & Absent \\
$50 \mathrm{mg} / \mathrm{kg}$ & $2.33 \pm 0.88$ & $1.67 \pm 0.67$ & Present \\
$100 \mathrm{mg} / \mathrm{kg}$ & $1.67 \pm 0.17$ & $1.27 \pm 0.33$ & Present \\
\hline
\end{tabular}

Table 5: Effect of methanol extract of Pausinystalia yohimbe root on spermatogenic elements in male rats Size of seminiferous tubules $(\mu \mathrm{m}) \quad$ Number of spermatogenic elements

\begin{tabular}{lllll} 
& Length & Breadth & Spermatogonia & Spermatocyte \\
\hline Negative control & $240.2^{\mathrm{d}} \pm 48.9$ & $110.4 \pm 29.4$ & $17.56 \pm 2.67$ & $72.26^{\mathrm{c}} \pm 4.77$ \\
Sildenafil citrate $(5 \mathrm{mg} / \mathrm{kg})$ & $308.8^{\mathrm{c}} \pm 415$ & $104.0 \pm 29.9$ & $11.56 \pm 1.99$ & $107.46^{\mathrm{b}} \pm 6.07$ \\
$25 \mathrm{mg} / \mathrm{kg}$ & $312.8^{\mathrm{c}} \pm 36.5$ & $108.0 \pm 23.0$ & $12.66 \pm 1.66$ & $110.16^{\mathrm{b}} \pm 5.31$ \\
$50 \mathrm{mg} / \mathrm{kg}$ & $326.6^{\mathrm{b}} \pm 56.3$ & $113.0^{\mathrm{a}} \pm 26.3$ & $12.65 \pm 1.08$ & $118.16^{\mathrm{a}} \pm 5.12$ \\
$100 \mathrm{mg} / \mathrm{kg}$ & $336.8^{\mathrm{a}} \pm 76.5$ & $116.0^{\mathrm{a}} \pm 27.4$ & $12.42 \pm 1.19$ & $122.18^{\mathrm{a}} \pm 7.61$ \\
\hline
\end{tabular}

$(n=5), p<0.05-$ Significant, $p>0.05-$ Not Significant

Different letters in superscript across the columns are significant from others

Table 6: Effect of Pausinystalia yohimbe methanol root extract on sperm parameters

\begin{tabular}{llll}
\hline Groups & Progressive motility $(\%)$ & Non- progressive motility $(\%)$ & Sperm count $\left(\mathbf{m i l l i o n}^{\mathbf{m m}} \mathbf{m}^{\mathbf{3}}\right)$ \\
\hline Negative control & $61.67 \pm 9.80$ & $25 \pm 9.57$ & $105.83^{\mathrm{d}} \pm 27.52$ \\
Sildenafil citrate $(5 \mathrm{mg} / \mathrm{kg})$ & $45 \pm 9.57$ & $35 \pm 6.71$ & $125.33^{\mathrm{c}} \pm 39.76$ \\
$25 \mathrm{mg} / \mathrm{kg}$ & $37.5 \pm 8.54$ & $63.33 \pm 13.33$ & $135.83^{\mathrm{c}} \pm 51.24$ \\
$50 \mathrm{mg} / \mathrm{kg}$ & $44 \pm 12.08$ & $45 \pm 11.18$ & $149.50^{\mathrm{b}} \pm 38.46$ \\
$100 \mathrm{mg} / \mathrm{kg}$ & $62 \pm 4.90$ & $33.33 \pm 9.89$ & $176.83^{\mathrm{a}} \pm 42.41$ \\
\hline
\end{tabular}

$(\mathrm{n}=5), p<0.05-$ Significant, $p>0.05-$ Not Significant

Different letters in superscript across the columns are significant from others 


\subsection{Histopathological studies of testes}

The testis section of control group animals showed normal histological texture. The diameter of seminiferous tubules varied within a range. The tubules having maximum diameter, were not abundant but textured within range. The cuboidal germinal epithelium exhibited normal shape and size. Sertoli cells had many cytoplasmic processes which were normal in size. Spermatozoa were embedded in the sertoli cells and showed normal cytoplasmic granulation. Leydigs cells had normal nuclear size. Luminal part of the tubules were normal in number with bundles of spermatozoa. Spermatozoa with long tail with small distinct head were visible microscopically (Plate 1). The extract treated group of rats showed pronounced effects in terms of testis weight and non-histological alterations, as evident in Plates 3-5, the administration of $P$. yohimbe root extract at all dose levels, revealed sperm cells in normal sequential maturation coupled with normal cytoplasmic granulation, and seminiferous tubules with spermatogenic series and interstitial spaces. Also, increment in the volume of cells and nucleus was strongly suggestive of steroid synthesis under the direct or indirect influence of the extract. Almost all tubules were overcrowded with sperm bundles. Histoarchitecture of the standard drug group also exhibited similar profile (Plate 2).

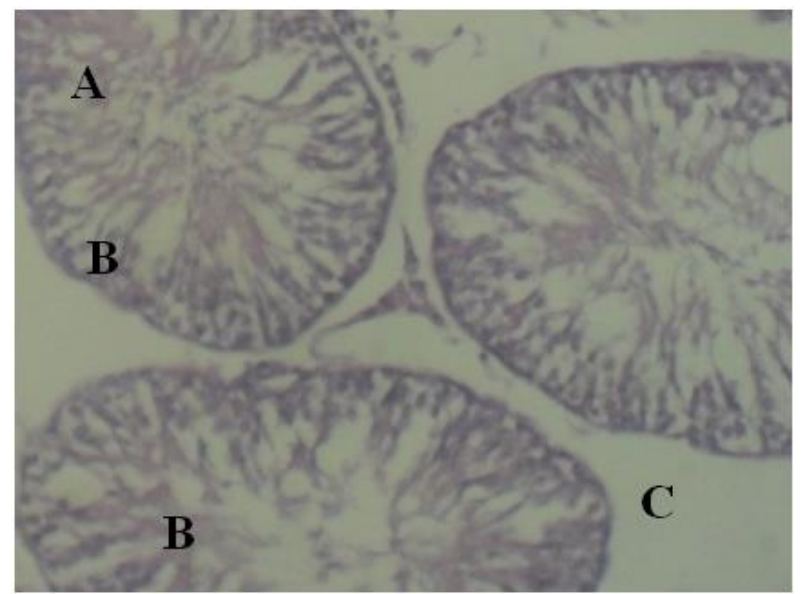

Plate 1: Histoarchitecture of eosin stained testis tissue section of negative control group at $\mathrm{X} 100 . \mathrm{A}=$ Seminiferous tubules; $\mathrm{B}=$ Spermatogenic series; and $\mathrm{C}=$ Interstitial spaces

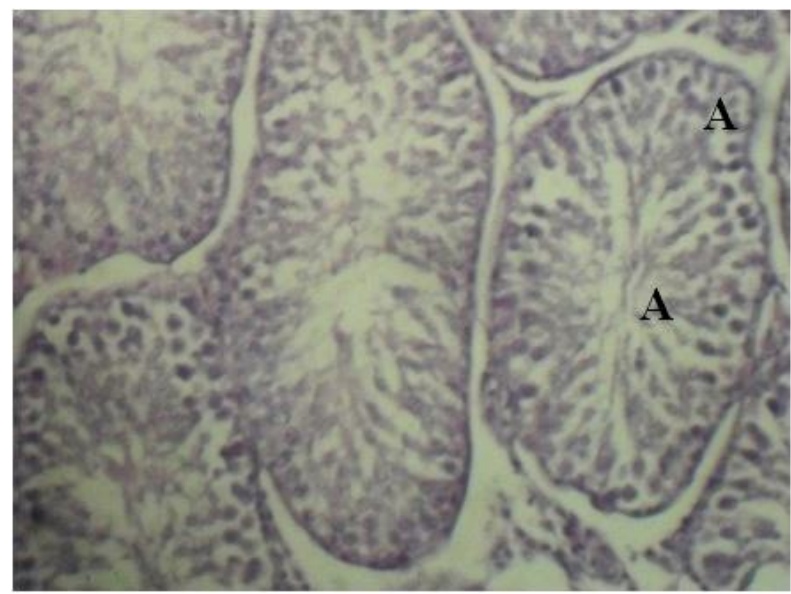

Plate 2: Histoarchitecture of eosin stained testis tissue section of 5 $\mathrm{mg} / \mathrm{kg}$ of Sildenafil citrate treated group at X 100. A = Seminiferous tubules

\section{Discussion}

The present investigations bring forth the spermatogenic activity of methanol extract of roots of Pausinystalia yohimbe in albino rats. Spermatogenesis involves a complex interplay between the structural elements of testis and the endocrine system. Hypothalamic gonadotrophic releasing hormone induces pituitary gonadotrophin (27).

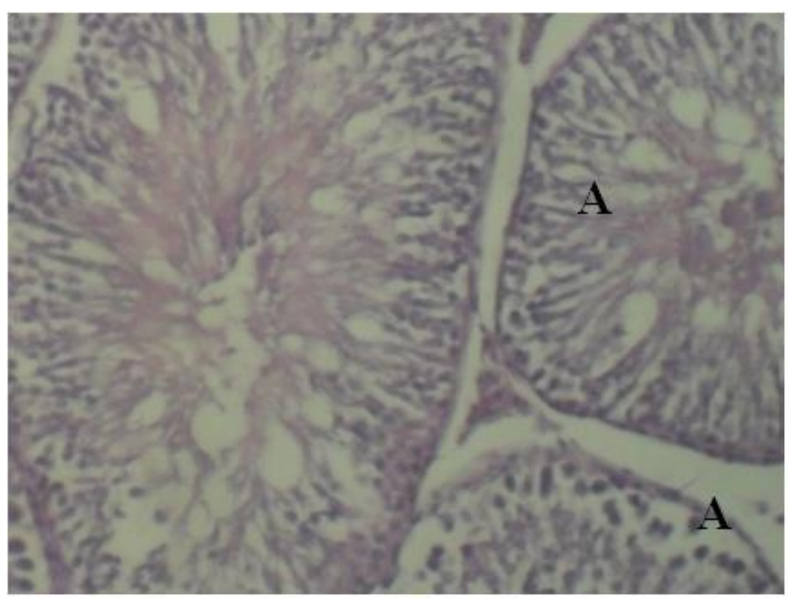

Plate 3: Histoarchitecture of eosin stained testis tissue section of 25 $\mathrm{mg} / \mathrm{kg}$ of Pausinystalia yohimbe methanol root extract treated group at $\mathrm{X}$ 100. $\mathbf{A}=$ Seminiferous tubules with spermatogenic series of sperm cells in normal sequential maturation and interstitial spaces

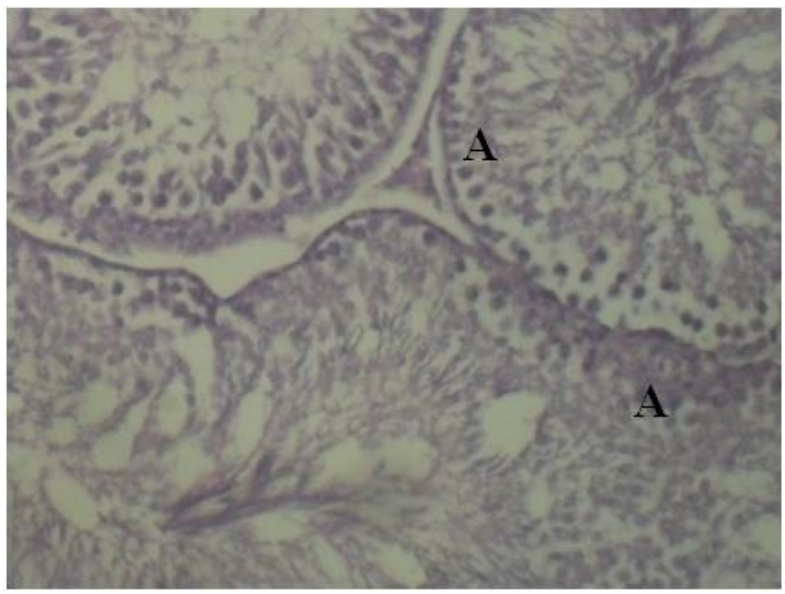

Plate 4: Histoarchitecture of eosin stained testis tissue section of 50 $\mathrm{mg} / \mathrm{kg}$ of $P$. yohimbe methanol root extract treated group at X 100 . A $=$ Seminiferous tubules with spermatogenic series of sperm cells in normal sequential maturation and interstitial spaces

Meanwhile, it has been reported in earlier research work that successful fertility depends on various factors including sperm quality and quantity, hormones, antioxidative status; and that bioavailability of testosterone is not only important for the maintenance of structural integrity of the testis and accessory sex organs and maintenance of spermatogenesis, but also essential for expression of secondary sex characters (28). Abundance of spermatozoa in seminiferous tubules clearly indicates spermatogenesis which is regulated by hormone (29). Hypertrophy of Leydigs cell is also suggestive of steroids synthesis. Earlier phytochemical investigations have shown the presence of cardiac glycosides, saponins, alkaloids, phenols, flavonoids, tannins and steroids (30) in roots of Pausinystalia yohimbe methanol extract. It is likely 
that these steroidal constituent coupled with other biomolecules increases the steroidogenesis and elevate androgen levels which results in observed effects i.e., spermatogenesis and sexual orientation activities. Involvement of hypothalamo-pituitary axis by way of follicle stimulating hormone impact cannot be ruled out. Root of source material under investigation has been demonstrated to have antioxidant properties in-vitro and in-vivo (16).

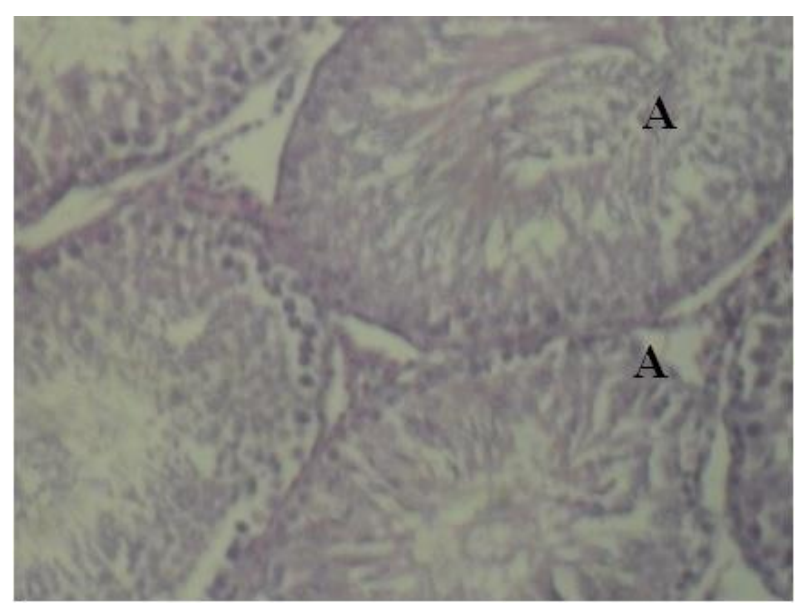

Plate 5: Histoarchitecture of eosin stained testis tissue section of 100 $\mathrm{mg} / \mathrm{kg}$ of $P$. yohimbe methanol root extract treated group at X 100. A $=$ Seminiferous tubules with spermatogenic series of sperm cells in normal sequential maturation and interstitial spaces

The phenol and phenolic glycoside shows antioxidative property (31). These antioxidant defence systems are of major importance because peroxidative damage is currently regarded as the single most important cause of impaired testicular function underpinning the pathological consequences of a wide range of conditions from testicular torsion to diabetes and xenobiotic exposure (32). In a normal situation, the antioxidant mechanisms present in the reproductive tissues and their secretions are likely to quench these reactive oxygen species (ROS) and protect against oxidative damage to gonadal cells and mature spermatozoa (33). Antioxidant compounds also alter androgen level (17), and changes in androgen level like testosterone, may be responsible for spermatogenesis.

Reduced number of spermatozoa, mal-formed spermatozoa or their reduced or insufficient motility are the leading causes of disturbed fertility or infertility in patient. Fertilization is primarily dependent on sperm motility and membrane integrity (34). Most commonly, male factor infertility is described in terms of abnormal sperm concentration (oligospermia), impaired sperm motility (asthenospermia) or teratospermia (abnormal sperm morphology). Oligospermia is the presence of less than 20 million sperm per concentration in a sperm specimen. According to the criteria for the standard value on sperm parameters, impaired sperm motility refers to sperm motility $<40 \%$ and the term impaired sperm morphology is applied if normal form is $<30 \%$. Such findings are associated with impaired fertility (35). It is universally accepted that semen analysis is one of the most important and common tests to evaluate the potential fertility of a man, which provides both quantitative and qualitative information (36).

Sperm motility studies identify the number of motile (moving) sperm seen in an ejaculate specimen. Many reports in the literature also consider "normal" sperm motility to be
$60 \%$ or greater. However, some studies, in agreement with many others have found $40 \%$ or greater sperm motility to be "normal" (37). This study however, revealed that the sperm motility in the extract treated groups at the doses of $50 \mathrm{mg} / \mathrm{kg}$ and $100 \mathrm{mg} / \mathrm{kg}$ body weight showed increased or improved activation of testicular function, which is an indication of the degree of spermatogenesis. The decreased progressive sperm motility and increased non-progressive sperm motility observed at the dose of $25 \mathrm{mg} / \mathrm{kg}$, suggest that the methanol extract of Pausinystalia yohimbe root at the aforementioned dose could decrease steroidogenesis and sperm maturation as also reported by Kim and Moley (38). The results on sperm motility are comparable to the study conducted by Ogwo et al. (39), where sperm motility significantly improved in the treatment groups of rats, while working on the semen quality in male albino rats fed with various concentrations of Pausinystalia yohimbe back powder (Burantashi). In contrast, significant reduction in sperm motility after administration of Pausinystalia yohimbe stem bark extract was also observed in rats by Ajonuma et al. (40), while working on adverse effects of prolonged use of Pausinystalia yohimbe on sperm and reproductive organs in rats.

There are reports in the literature that Pausinystalia yohimbe back powder (Burantashi), and Pausinystalia macroceras improves sperm counts (significantly) (39), and the exocrine function of the testes (25). The results on sperm counts observed in this study, seems to corroborate with this fact because methanol extract of Pausinystalia yohimbe root had improved effect on the sperm count of experimental animals, thereby supporting the extracts' potential for boosting sperm quality (count and motility). In addition, the improvement in sperm count indicates the increased activity of hormonal producing cells (41)

\section{Conclusions}

In conclusion, the present study predicted that from the data provided in this investigation, the extract may thus, provide an alternative therapy for management of infertility and reproductive indexes due to reduced spermatogenesis. Further studies are necessary to elucidate the compounds of the methanol extract of the plant material responsible for enhances spermatogenesis in rats.

\section{Acknowledgements}

I am grateful to my family especially my Mum for providing necessary support during the course of this research. Also, I acknowledged Mr. Gabrieel Benjamen of the Phytomedicine Unit, Department of Plant Biology and Biotechnology, University of Benin, Nigeria for the technical assistant rendered.

\section{Ethical issue}

Authors are aware of, and comply with, best practice in publication ethics specifically with regard to authorship (avoidance of guest authorship), dual submission, manipulation of figures, competing interests and compliance with policies on research ethics. Authors adhere to publication requirements that submitted work is original and has not been published elsewhere in any language.

\section{Competing interests}

The authors declare that there is no conflict of interest that would prejudice the impartiality of this scientific work. 


\section{Authors' contribution}

All authors of this study have a complete contribution for data collection, data analyses and manuscript writing.

\section{References}

1. Yakubu MT, Akanji MA, Oladiji AT. Male sexual dysfunction and methods used in assessing medicinal plants with aphrodisiac potentials. Pharmacognosy Review 2007;1: 49-56.

2. Fullick, A. Biology. Heinenmann Advanced Sciences, Oxford, United Kingdom.1994; 332p.

3. Yakubu MT, Akanji MA. Effect of aqueous extract of Massularia acuminata stem on sexual behaviour of male wistar rats. Evidence-Based complementary and Alternative Medicine 2011;10: 1-11.

4. Sharanabasappa AP, Sujaya M, Saraswati BP. Aphrodisiac and phytochemical studies of Cocculus hirsutus extracts in albino rats. Asian Pacific Journal of Reproduction 2014;3(1): 23-29.

5. Hall PF. Testicular steroid synthesis: Organization and regulation. In: Knobil, E, Neil, JD. (Eds.) Physiology and Reproduction. Raven Press, New York. 1994;13-35.

6. Chemes HE, Dym M, Raj HG. The roles of gonadotropins and testosterone on initiation of spermatogenesis in immature rat. Biol. Reprod. 1997;21: 241-248.

7. Jorsararei SGA, Yousefnia-Pasha YR, Zainalzadeh M, Moghadamnia AA. The effects of methanolic extracts of ginger (Zingiber officinale) on human sperm parameters: An in vitro study. Pakistan Journal of Biological Sciences 2008;11(13): 1723-1727.

8. Chen JC, Xu MX, Chen LD, Chen YN, Chiu TH. Effect of Panax notoginseng extracts on inferior sperm motility in vitro. Am. J. Chin. Med. 1999;27(1): 123-128.

9. Malviya N, Jain S, Gupta VB, Vyas S. Indigenous herbal remedies used by tribals of Madhya Pradesh for improving their sexual performance and problem associated with sexuality. International Journal of Research in Ayurveda and Pharmacy, 2011;2(2): 399402.

10. Dohle GR, Smit M, Weber RFA. Androgens and male fertility. World Journal of Urology 2003;21(5): 341-345.

11. Snyder PJ. Clinical use of androgens. Annual Review of Medicine 1984;35: 207-217

12. Zvara P, Sioufi R, Schipper HM, Begin LR, Brock GB. (1995) Nitric oxide mediated erectile activity is a testosterone dependent event: a rat erection model. International Journal of Impotence Research 1995;7(4): 209-219.

13. Yakubu MT, Afolayan AJ. (2009). Effect of aqueous extract of Bulbine natalensis stem on the sexual behaviour of male rats. International Journal of Andrology 2009;32: 629-636.

14. Anonymous. Pausinystalia yohimbe. [Available at: https://en.wikipedia.org/wiki/ Pausinystalia yohimbe] [Assessed: September 23, 2019].

15. Erhabor JO, Idu M, Ojatula AO. Ethnomedicinal survey of plants used in the treatment of male sexual dysfunction among the Ilaje people of Ondo State, Nigeria. In: Kumar, S. (Editor) Recent Advances in Ethnobotany. Deep Publications, Paschin Vihar, New Delhi, India. 2015;16-21

16. Ojatula AO. "Bioactivity and safety assessment of Pausinystalia yohimbe (K. Schum.) Pierre ex Beille root extract on male sexual and spermatic parameters in wistar rats," Unpublished Ph.D. Dessertation, phytomedicine, University of Benin, Benin City, Nigeria. 2017;266p

17. Islam MW, Tariq M, Ageel AM, Al-said MS, Al-Yhya AM Effect of Salvia hematodes on sexual behavior of male rats. Journal of Ethnopharmacology 1991;33: 67-72.

18. Sharma V, Thakur M, Chavhan SN, Dixit VK. Valuation of the anabolic aphrodisiac and reproductive activity of Anacyclus pyrethrum in male rats. Scientia Pharmacetutica 2009;77: 97110

19. Zade V, Dabhadkar D. Evaluation of potential aphrodisiac activity of Hibiscus cannabinus seeds in male albino rats. International
Journal of Pharmaceutical and Biological Sciences 2013;4(3): 276-286.

20. Zade V, Dabhadkar D, Thakare V, Pare S. Evaluation of potential aphrodisiac activity of Moringa oleifera seed in male albino rats. International Journal of Pharmacy and Pharmaceutical Sciences 2013;5(4): 683-689.

21. Saksena S, Dixit VK. Role of total alkaloids of Mucuna pruriens Baker in spermatogenesis in albino rats. Indian J. Nat. Prod. 1987;2: 3-7.

22. Thakur M, Dixit VK. Effect of Chlorophytum borivilianum on androgenic and sexual behaviour in male rats. Indian Drugs 2006;43(4): 300-306.

23. Dostal LA, Faber CK, Zandee J. Sperm motion parameters in vas deferens and cauda epididymal rat sperm. Reproduction and Toxicology 1996;10: 231-235.

24. World Health Organization. WHO Laboratory Manual for the Examination of Human Semen and Sperm-Cervical Mucus Interaction $\left(4^{\text {th }}\right.$ edition). Cambridge University Press, New York. $1999 ; 138$ p.

25. Ikebuaso AD, Yama OE, Duru FIO, Oyebadejo SA. Experimenta testicular torsion in a rat model: effects of treatment with Pausinystalia macroceras on testis functions. Journal of Reproduction and Infertility 2012;13(4): 218-224.

26. Priyadarshani N, Varma MC. Effect of Moringa oleifera leaf powder on sperm count, histology of testis and epididymis of hyperglycaemic mice. American International Journal of Research in Formal, Applied and Natural Sciences 2014;1: 7-13.

27. McLachlan RI. The endocrine control of spermatogenesis. Journal of Clinical Endocrinology and Metabolism 2000;14(3): 345-362.

28. Meena R, Sreenivasula RP. Do phytoestrogens affect reproductive performance in male rats? Journal of Infertility and Reproductive Biology 2014;2(1): 1-5.

29. Hadziselimovie F, Herzog B. Treatment with a luteinizing hormone-releasing hormone analogue after successful orchiopexy markedly improves the change of fertility later in life. Journal of Urology 1997;158(3): 1193-1195.

30. Ojatula AO. Biomolecules and phytominerals profiling of Pausinystalia yohimbe (K. Schum.) Pierre ex Beille root extract. Journal of Functional Materials and Biomolecules 2019;3(2): 312-316.

31. Wu Q, Fu DX, Hou AJ, Lei GQ, Liu ZJ, Chen JK, Zhou TS. Antioxidative phenols and phenolic glycosides from Curculigo orchioides. Chem. Pharm. Bull. 2005;53(8): 1065-1067.

32. Aitken RJ, Roman SD. Antioxidant system and oxidative stress in the testes. In: Cheng, CY. (Editor) Molecular Mechanism in Spermatogenesis. Landes Bioscience, United Kingdom. 2007;1121.

33. Sikka SC. Relative impact of oxidative stress on male reproductive function. Curr. Medici. Chem. 2001;8: 851-862.

34. Zheng RL, Zheng $\mathrm{H}$. Effects of ferulic acid on fertile and asthenozoospermic infertile human sperm motility, viability, lipid peroxidation, and cyclic nucleotides. Free Radical Biology and Medicine, 1996;22: 581- 586.

35. Ekwere OE, McNeil TR, Okwuasaba KF. The effect of Ricinus communis on semen parameters: a comparative study. Journal of Physics Conference Series 2011;1: 7-11.

36. Sheykhhasan M, Ghiasi M. Semen quality and age-dependent changes among male participants with normal sperm count in Qom, Iran. Journal of Infertility and Reproductive Biology 2016;4(2): 35-39.

37. Anonymous. Sperm and semen testing and evaluation. [Available at: http://www.fertility-docs.com/programs-and-services/spermevaluation/sperm-ad-semen-testing.php] [Accessed: September 4 2015].

38. Kim ST, Moley KH. Paternal effect on embryo quality in diabetic mice is related to poor sperm quality and associated with decreased glucose transporters expression. Reproduction 2008; 136: 313-322.

39. Ogwo EU, Osim EE, Nwankwo AA, Ijioma SN. Semen quality in male albino rats fed with various concentrations of Pausinystalia 
yohimbe bark powder (burantashi). Journal of Medical and Dental Science Research 2016;3(1): 16-24.

40. Ajonuma LC, Bamiro AS, Makonjuola SL, Salami M, Carew E, Umoren GA, et al. Adverse effects of prolonged use of Pausinystalia yohimbe on sperm and reproductive organs in rats. Journal of Health, Medicine and Nursing 2017;38: 33-43.

41. Ahmed KA, Venkataraman BV. (1999). Assessment of a polyherbal ayurvedic medicine for sexual activity in rats. Indian Drugs 1999;36(9): 579-582. 